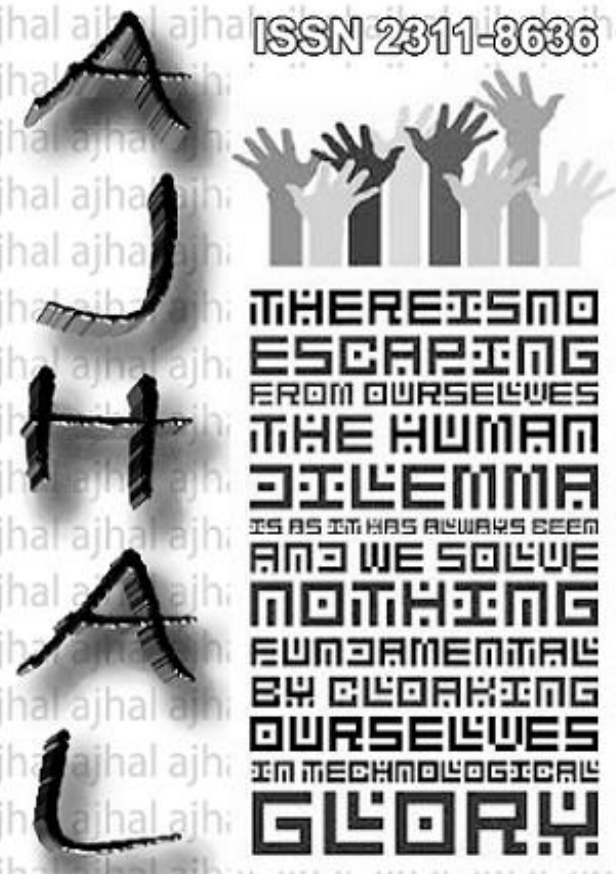

Vol 3, No. 2/2016

Asjan Journal of Humanity, Art and Liteigatul"e 


\title{
Knowledge and Attitudes about HIV/AIDS among the Slum Dwellers in Dhaka City
}

\section{Abul Khair Basher ${ }^{1}$, Fatema Tania ${ }^{2 *}$}

ISSN: 2311-8636 (Print)

ISSN: 2312-2021 (Online)

DOI prefix: $\mathbf{1 0 . 1 8 0 3 4}$

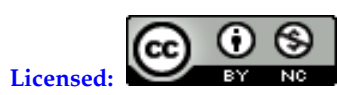

Source of Support: Nil

Conflict of Interest: None Declared

${ }^{*}$ Email for correspondence:

taania_kh@yahoo.com

\author{
${ }^{1}$ Senior Sector Specialist, TB Control Programme, BRAC, Mohakhali, \\ Dhaka-1212, BANGLADESH \\ ${ }^{2}$ Senior Lecturer, Department of Applied Sociology, ASA University \\ Bangladesh, BANGLADESH
}

\section{ABSTRACT}

HIV/AIDS is found commonly among sexually active young adults, many of whom may live in slum. This group may serve as the gateway for HIV transmission to the general population because of their vulnerable lifestyle, and lack of information about the disease and its prevention. Cross-sectional questionnaire-based study of 116 slum dweller was carried out in a selected slum area. Among them highest age group is $43.10 \%(26-35)$ and the Mean age of population is $26.5 \mathrm{SD} \pm 5.34$. $(43.10 \%)$ of the respondents are male and were $(56.90 \%)$ of the respondents are female. The large numbers of the respondents $(43.10 \%)$ cannot read and write, $34.48 \%$ people have primary education. Most of the respondents (39.67\%) income level is (2000-5000) and Median income is $8500 \mathrm{SD} \pm 4514.9$. Table shows that $83.62 \%$ were married, $72.41 \%$ respondents live in the nuclear family and $56.9 \%$ respondents have family member of $2-4$ persons. Large numbers $(32.76 \%)$ of the respondents are working as house maid. $87.93 \%$ of the respondents heard the name of HIV/AIDS and the source of information was Media (Radio, TV, newspaper.). Majority (60.34\%) respondents thought that HIV/AIDS is a disease but $10.34 \%$ seems that it is a curse of God. Out of total respondents 66 thought that unsafe physical relation is the foremost source of infection and about prevention $46.55 \%$ respondents told that protected sexual measure can prevent the disease. Majority (64.66\%) of the respondents don't know signs and symptoms of $\mathrm{HIV} /$ AIDS but rest of them thought that Rapid weight loss, Dry cough for more than $2 / 3$ months, Recurring fever for more than $2 / 3$ months and Diarrhea lasting more than a week are the symptom of HIV / AIDS. Most (41.38\%) of the respondents told that HIV / AIDS cured by treatment and $89.66 \%$ respondents thought that the patients should not isolated from family. Their knowledge level is seems too reduced.

Key Words: Knowledge, Attitude, HIV / AIDS, Slum dwellers

\section{INTRODUCTION}

Acquired immune deficiency syndrome (AIDS) pandemic is an infectious disease caused by human immunodeficiency virus (HIV) that has created a global catastrophe. Once HIV starts damaging the human immune system, it ultimately develops AIDS and ends in death. It is a condition when the immune system begins to fail and leads to live- 
threatening opportunistic infections. The existence of HIV/AIDS poses a serious challenge to the human being and its impact on a country is tremendous. HIV is a retrovirus that can lead to AIDS and considered as a severe global health problem. The pandemic has affected most countries in the world. In 2010, the total number of people living with HIV was 34.0 million in which with adult prevalence rate $0.8 \%$, in which women prevalence rate $0.6 \%$, newly infected with HIV was 2.7 million, the number of deaths due to AIDS was 1.8 million. Every day, over 6800 persons become infected with HIV and over 5700 persons die from AIDS, mostly because of inadequate access to HIV prevention and treatment services. In many developing countries, HIV prevalence was above $1 \%$, but in none of the developed countries, HIV prevalence has ever crossed the 1\% mark (UNAIDS, 2012).

In October 1989, the first HIV positive case was detected in Bangladesh. The person was a foreigner. The first Bangladesh HIV positive and AIDS patients were noticed in May 1990. The HIV positive case a migrant worker and the AIDS patient was a seaman. He has been treated under the close observation of National AIDS Committee (NAC) of Bangladesh and later died in March 1991. The overall prevalence of HIV in Bangladesh is relatively little, but the infection has reached significant proportions in certain high-risk groups and may soon spread to other groups. Most of the people who are engaged in high-risk behaviors do not know how HIV has been transmitted and are not aware that their behavior puts them at risk. In Bangladesh, the HIV prevalence in the general population appears low $(<0.2 \%)$, and is estimated as $(1 \%)$ in all risk groups except for injecting drug users (IDU) $(7 \%)$. Although the exact number of HIV cases is not known, by 2010, total 2088 cases of HIV have been confirmed. Among them 250 cases of HIV had been newly diagnosed and 850 had developed AIDS. Then143 was newly diagnosed and 241 had died where 39 new death occurred, a much higher number than are $54(21.6 \%)$ and $53(21.2 \%)$ HIV- infected people of the entirety newly diagnosed HIV population in 2010 respectively. Again, among the total newly diagnosed HIV group in 2009, 82.4\% belonged to $16-45$ years of age, $67.6 \%$ was male, and $30.4 \%$ was female and most of them $77.2 \%$ were married. So, it is clear that married women are the most vulnerable group, and they are at greater risk of acquisition and transmission HIV and AIDS epidemics (MOHFW, 2011).

Bangladesh is considered a high-risk country for several reasons. Bangladesh is a geographically vulnerable to HIV/AIDS due to its high prevalence to India, Myanmar, Nepal and Thailand. Bangladesh is bordered by India on the East, West and North and a border strip with Myanmar on the South. India alone has 2.5 million people living with $\mathrm{HIV} / \mathrm{AIDS}$ with a prevalence rate of $0.36 \%$ which is more than half of all the people living with HIV/AIDS in Asia. Bangladesh has a close trade ties with Thailand. The epidemic is severe in all these countries. But knowledge about this virus and its transmission still remains incomplete. Among the adolescents, girls are more vulnerable to sexually transmitted diseases (STDs) including HIV/AIDS, especially through heterosexual intercourse with others than their male counterparts. All these potential factors fuel to the rise in HIV acquisition and transmission. If this situation continues, Bangladesh will face a crisis, as a developing country, it does not have the resources to tackle. It will be unable to mitigate the harmful impact of widespread HIV/AIDS, especially be unable to afford the medication costs. Several countries, including Thailand and Uganda, have successfully decreased the spread of HIV by aggressive efforts in this regard. Consequently, there is an urgent need for a comprehensive prevention program to control the spread of HIV / AIDS in Bangladesh. In this critical situation, public awareness can play a dominating role in preventing HIV/AIDS epidemic. Useful and fruitful media campaigns are strongly 
suggested for creating knowledge and awareness to be controlled the spread of HIV and AIDS are increasing the likelihood of HIV transmission as well as having other reproductive health consequences of ever- married women (Rahman, 2007).

In recent years, knowledge about HIV and AIDS has increased across the country. Most adolescents were aware of HIV / AIDS. Study findings suggest that ninety-three percent of the male and 78 percent of the female adolescents either knew about or had heard of HIV. Similarly, a large number of the adolescents had knowledge on routes of HIV transmission. Most (90 percent) adolescents could correctly mention that the major routes of HIV transmission are: receiving the HIV-infected blood transfusion, using non-sterilized syringe, having unsafe sex, and having sex with multiple sexual partners. However, the adolescents had some misconceptions about the routes of HIV transmission. Although the knowledge of transmission is high but still a significant percentage (15 percent) of adolescent did not know how to prevent it. It was also found that the proportion having knowledge on the prevention of HIV / AIDS was almost equal between the male and the female adolescents, except the use of condom during sex. It is critical to improve the knowledge of spread as well as prevention of HIV among the all age group. (MOHFW, 2011).

\section{OBjectives OF the Study}

- $\quad$ To assess the level of knowledge about HIV / AIDS among the slum dwellers in Dhaka city

- To explore the attitudes of respondents on HIV/AIDS

- To find out the socio-demographic characteristics of the respondents

\section{LITERATURE REVIEW}

The HIV epidemic represents one of the today's most profound challenges in improving global health. Women represent a growing proportion between people living with HIV and AIDS, and the ratios of infected men to women have been particularly skewed among young people. At the end of 2006, in Sub-Sahara Africa, for every HIV-infected young man (15-24- year- old) there were nearly three infected young women. Halting further expansion of the HIV pandemic within the next decade is a top priority for governments and civil society the world over and one of eight Millennium Development Goals set by the United Nations and unusual prevention efforts is reducing women's risk of HIV and other sexually transmit infections (United Nations, 2007).

At the international level, international development agencies have played a large role in development activities in Bangladesh since Independence in 1971. Since HIV/AIDS programs began in 1986, these programs have supported biomedical and behavioral interventions, such as the promotion of condom and behavior change interventions, for high-risk groups. These activities are relatively more amenable to quantitative evaluation, such as project targets framed regarding 'number of condoms distributed' or 'number of HIV information booklets produced and shared out'. It would appear then that, as a result of edged advocacy, the targeted high-risk groups would get labeled in the public mind as carriers of HIV infection and get further stigmatized. Thus, unintentionally, such internationally funded programs are creating further social exclusion. Such exclusion that is not deliberate has termed 'passive exclusion' (Estivill, 2003).

The main purposes of this study were to find out, by collecting data and the necessary information from sere-surveillances, published reports, and articles, what the prevalence of HIV / AIDS is, and what the acquisition and transmission routes are. In addition, trends in HIV-related risk behaviors among recognized high risk groups were observed, and 
estimations and projections of HIV transmission up to the year 2020 presented. The study results reveal that Bangladesh is a low prevalence country which is turning into one with a concentrated epidemic due to the high HIV prevalence rate of IDU (7\%) among the mostat-risk groups. Within this at-risk population, IDU have the highest prevalence rate of HIV transmission, followed by female sex workers, clients of sex workers, and men who have sex with men. If the transmission rate continues to increase, the situation will be uncontrolled. Therefore, there is an urgent need for a comprehensive prevention program to control the spread of HIV (Mandal, et al. 2009). The first case of HIV/AIDS in Bangladesh was detected in 1989. Since then 1495 cases of HIV/AIDS have been reported. However UNAIDS estimates that the number of people living with HIV in the country may be as high as 12,000 , which is within the range of the low estimate by UNICEF's State of the World's Children Report 2009. The overall prevalence of HIV in Bangladesh is less than $1 \%$, however, high levels of HIV infection have been found among injecting drug users. Although still considered to be a low prevalence country, Bangladesh remains extremely vulnerable to an HIV epidemic, given its dire poverty, overpopulation, gender inequality and high levels of transactional sex. It is estimated that without any intervention the prevalence in the general adult population could be as high as $2 \%$ in 2012 and $8 \%$ by 2025 .Bangladesh is in the unique position to succeed where several other developing countries have not: to keep the AIDS epidemic from expanding beyond this current level by initiating comprehensive and strategically viable preventative measures, avoiding a gradual spread of HIV infection from high-risk groups to the general population (Unicef, 2011).

Bangladesh is the seventh most populous country in the world with a population of about 161.3 million. According to the UNAIDS, 13,000 people were living with HIV in the country at the end of 2003. The impact of HIV/AIDS reaches every concern of society in Bangladesh. The level of knowledge of the population is thus an important measure for understanding the magnitude of the challenges by Government and Non-government organizations. So far, the disease has no any reliable antibiotic medicine till today, but cure for HIV/AIDS infection remains an elusive goal despite the significant impact of current treatments. This is because of the virus ability to adapt to and resist those dealings and bypass the immune systems natural defenses (Suhadolnik, 2007).

Bangladesh is in a precarious position in relation to the HIV/AIDS epidemic. Rates are currently low compared to the rest of the South Asian region, and the disease is relatively confined to small, high-risk populations - mainly injection drug users (IDUs) and commercial sex workers. Yet if steps are not taken quickly to keep the epidemic in check, it could easily spread to the general population as it has in other countries nearby. This would both increase the negative impact of HIV/AIDS and make it much harder to target for containment. Prevention will be the key to halting the spread of HIV infection through the implementation of communication and education programs aimed to change high-risk behavior. This paper proposes adoption of the FOMENT model to design a health communication campaign targeting the high-risk populations in Bangladesh (Haider, et al. 2008).

Although young Bangladeshis are at risk of HIV very few believe that 22 percent of unmarried males reported having premarital sex, almost 60 percent of whom had never used condoms. Women also require individual attention in HIV interventions in Bangladesh, given their social, economic and political status. Women's lower social and cultural status also causes them to have less access to education, employment opportunities and health care, including opportunities for HIV tests, counseling and medical care. The 
HIV prevalence among the general public is not completely known; currently available surveillance data only covers high-risk groups. Many HIV -positive people tested both in private and government facilities have seen their names and other personal details published in the local or national media. Social values, lack of adequate information, the stigma attached to HIV and AIDS, and the lack of confidentiality are not conducive in support of people, especially the younger population, to seek out HIV tests (Unicef, 2010).

\section{Methodology}

The quantitative cross sectional study has been conducted in two slums in Dhaka city. The target population has been selected from slum dwellers at Mohammmadpur and Agargaon areas in Dhaka city. This study has been conducted from February to April, 2014. Total sample size of this research was116. This study has assessed the knowledge and attitudes about HIV / AIDS among the slum dwellers.

The Quantitative research methods were applied to collect information. The instrument used for data collection was a self-developed, self- and researcher-administered standardized structured questionnaire. The purpose of the study has been briefly explained to the respondents, and strict confidentiality was assured

\section{LIMITATIONS OF THE STUDY}

The Quality of the research has limited due to the difficulties like:

- Time constraint is a huge problem.

- The respondents have not voluntarily given enough time. The Respondents are lowincome people, so they weren't available in all time.

\section{FINDING OF THE STUDY}

The present cross-sectional study undertaken to assess the knowledge and attitudes about HIV / AIDS among the slum dwellers in Dhaka city included a total 116 people.

Table 1: Distribution of respondents by their age, educational level, monthly income, marital status, type of family and Family members

\begin{tabular}{|c|c|c|}
\hline Variables & Frequency(n) & Percentage \\
\hline Age & & \\
\hline $15-25$ years & 38 & 32.76 \\
\hline $26-35$ years & 50 & 43.10 \\
\hline $36-45$ years & 28 & 24.14 \\
\hline \multicolumn{3}{|l|}{ Mean age $29.46 S D \pm 5.34$} \\
\hline Educational level & & \\
\hline Cannot read or write & 50 & 43.10 \\
\hline Primary & 40 & 34.48 \\
\hline Secondary & 20 & 17.25 \\
\hline Higher secondary \& above & 6 & 5.17 \\
\hline \multicolumn{3}{|l|}{ Monthly income (tk.) } \\
\hline No income & 28 & 24.14 \\
\hline $2,000-5,000$ & 46 & 39.67 \\
\hline $5,000-15,000$ & 32 & 27.58 \\
\hline $15,000-25,000$ & 10 & 8.61 \\
\hline
\end{tabular}




\begin{tabular}{|l|c|c|}
\hline Median income 8500 SD \pm 4514.9 & \\
\hline Marital status of respondents & & 83.62 \\
Married & 97 & 13.79 \\
Unmarried & 16 & 2.59 \\
Divorce & 03 & \\
\hline Types of family & & 72.41 \\
Nuclear family & 28 & 24.14 \\
Joint family & 4 & 3.45 \\
Others & & \\
\hline Family members & 66 & 56.9 \\
2-4 & 44 & 37.93 \\
5-7 & 6 & 5.17 \\
$8-9$ & 116 & 100 \\
\hline Total & \multicolumn{2}{|l}{} \\
\hline
\end{tabular}

According to the table 1 highest age group is $43.10 \%(26-35)$, and the Mean age of the population is $26.5 \mathrm{SD} \pm 5.34$. The large numbers of the respondents $(43.10 \%)$ cannot read and write, $34.48 \%$ people have primary education. Most of the respondents $(39.67 \%)$ income level of people is (2000-5000), and Median income is $8500 \mathrm{SD} \pm 4514.9$. The Table shows that $83.62 \%$ were married, $72.41 \%$ respondents live in nuclear family and $56.9 \%$ respondents have the family member of 2-4 persons.

Figure-1: Distribution of the respondents by sex

\section{Sex}

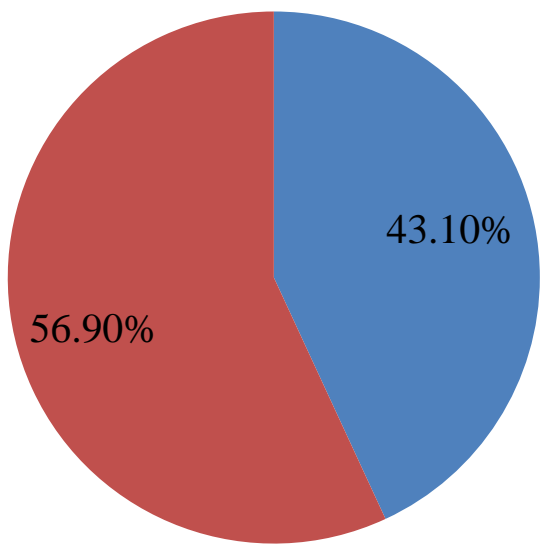

- Male

- Female

These figure- 1 shows that were $(43.10 \%)$ of the respondents are male and were $(56.90 \%)$ of the respondents are female. 
Figure-2: Distribution of the respondents by their religion

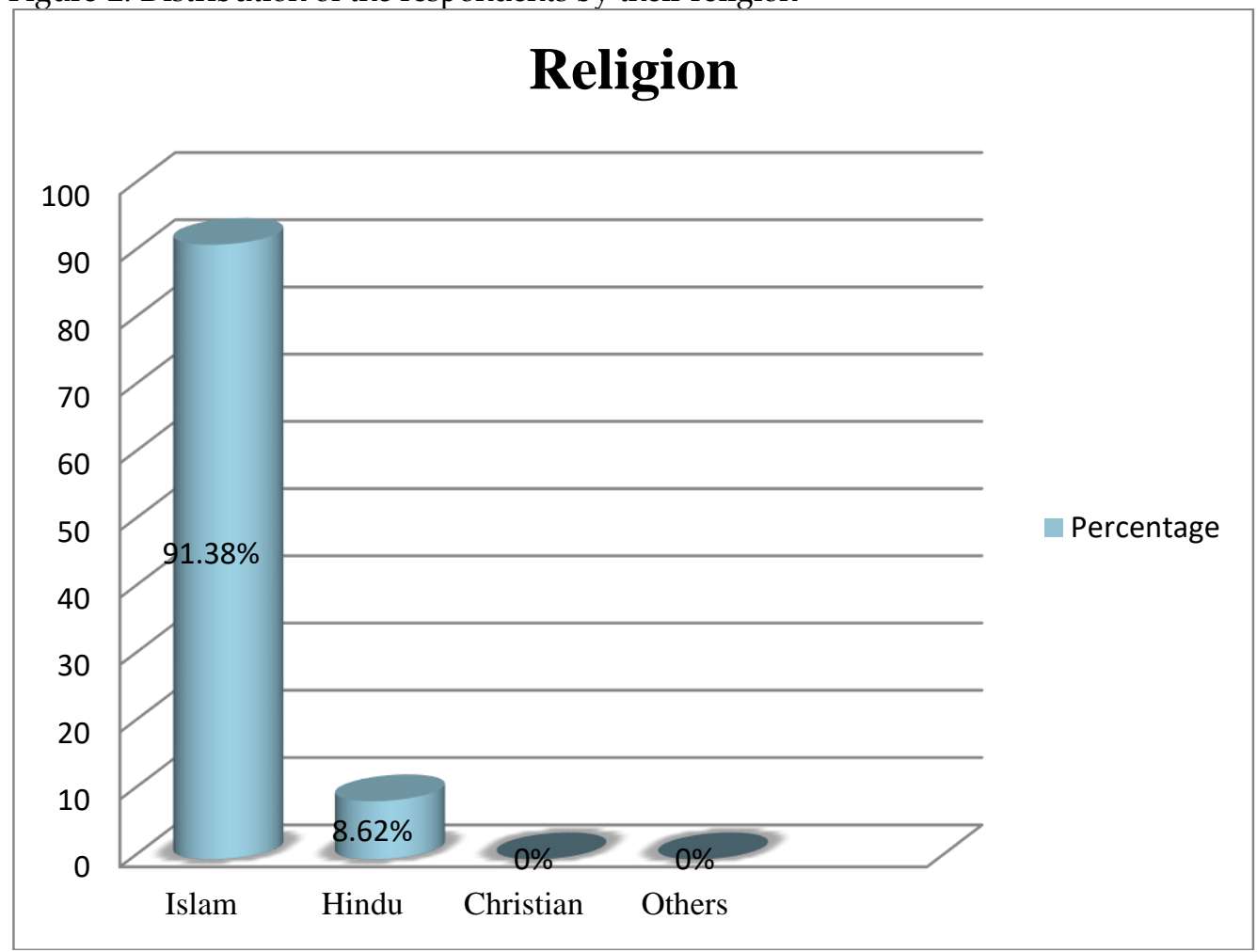

According to this figure-2, were 106 (91.38) of the respondents religion were Islam, and 10 (8.62) of the respondents were Hindu.

Table-2: Distribution of the respondents by occupation.

\begin{tabular}{|l|l|l|}
\hline Occupation & Frequency & Percentage \\
\hline Unemployed & 4 & 3.45 \\
\hline Student & 3 & 2.59 \\
\hline Business & 29 & 25 \\
\hline Job & 8 & 6.90 \\
\hline Cleaner & 2 & 1.72 \\
\hline House Wife & 17 & 14.66 \\
\hline House Maid & 38 & 32.76 \\
\hline Others & 15 & 12.93 \\
\hline Total & 116 & $100 \%$ \\
\hline
\end{tabular}

The table 2 shows that were the slum dwellers are very hard working. The both male and female are engaged in economic production. In this table, the large numbers $(32.76 \%)$ of the respondents are working into house maid. Another a big portion (25\%) is engaged in business. Very few of (3.45\%) respondents are unemployed. And most of the important parts of my study only one respondent are sex worker. 
Figure-3: Distribution of the respondents by hearing the name of HIV / AIDS

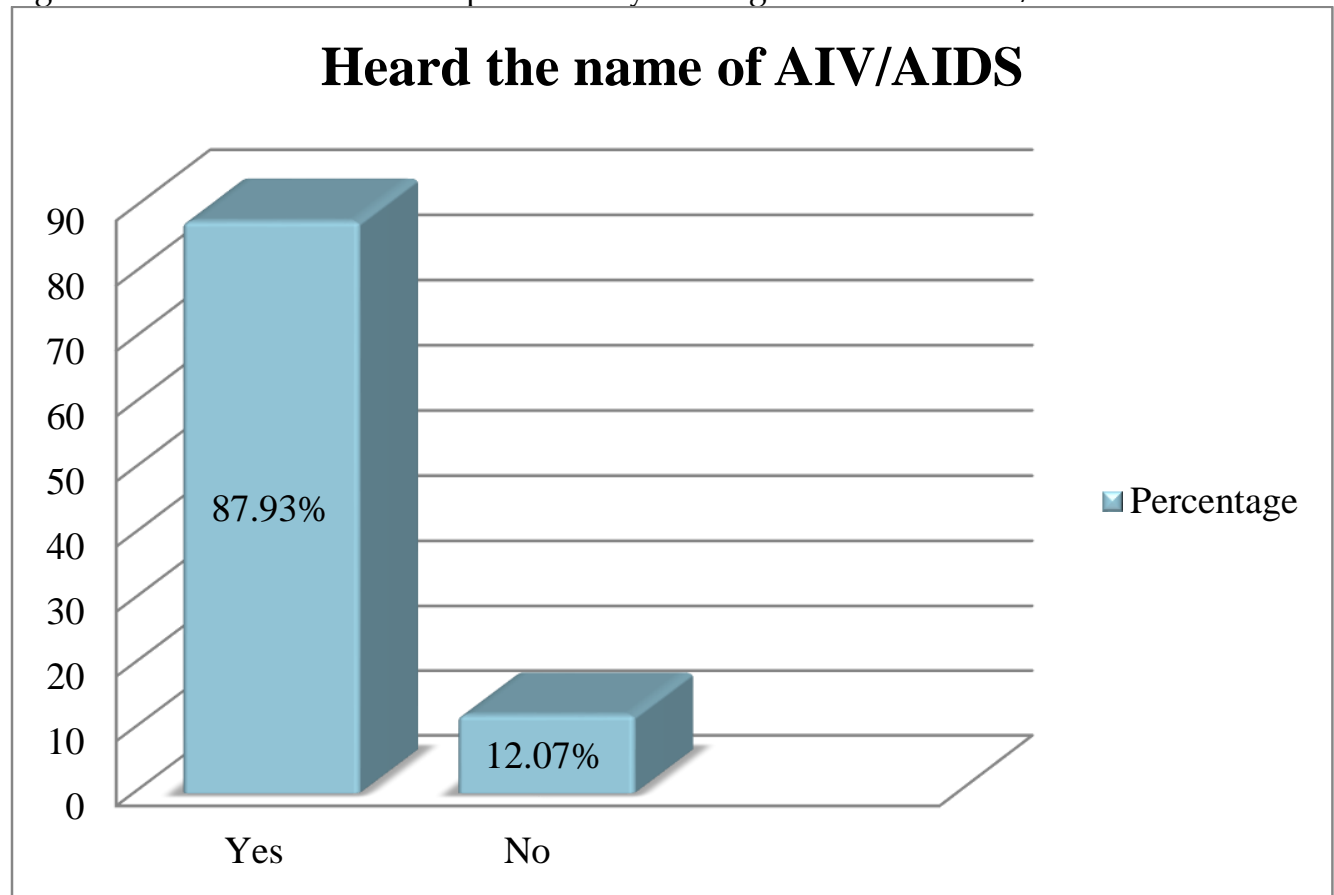

In this figure- 3 shows that were $(87.93 \%)$ of the respondents heard the name of HIV / AIDS and while $(12.07 \%)$ of the respondents did not know the name of HIV / AIDS.

Table-3: Distribution of the respondents by the source of information about HIV / AIDS.

\begin{tabular}{|l|l|l|}
\hline Source & Frequency & Percentage \\
\hline Media...(TV, Radio, News) & 72 & 62.07 \\
\hline Doctor/Health Worker & 10 & 8.62 \\
\hline NGOs Worker & 4 & 3.45 \\
\hline Cinema/Drama & 2 & 1.72 \\
\hline Seminar/Workshop & 14 & 12.07 \\
\hline Others & 14 & 12.07 \\
\hline Total & 116 & $100 \%$ \\
\hline
\end{tabular}

According to this table-3, were (62.07\%) of the respondents were heard by Media, $(8.62 \%)$ by Doctor, $(3.45 \%)$ by NGOs Worker, $(1.72 \%)$ by Cinema, $(12.07 \%)$ by Seminar \& others, and $(12.07 \%)$ by others.

Table-4: Distribution of the respondents by idea about HIV \& AIDS.

\begin{tabular}{|l|l|l|}
\hline HIV & Frequency & Percentage \\
\hline A Disease & 70 & 60.34 \\
\hline A Curse from God & 12 & 10.34 \\
\hline Don't Know & 34 & 29.32 \\
\hline Total & 116 & $100 \%$ \\
\hline
\end{tabular}

This table- 4 shows that the $(60.34 \%)$ of the respondents knowledge about HIV is a disease, $(10.34 \%)$ by a curse from God, and (29.32\%) told that they don't know about HIV. 
Figure-4: Distribution of the respondents by knowing the spreading source of HIV.

\section{HIV Spreads}

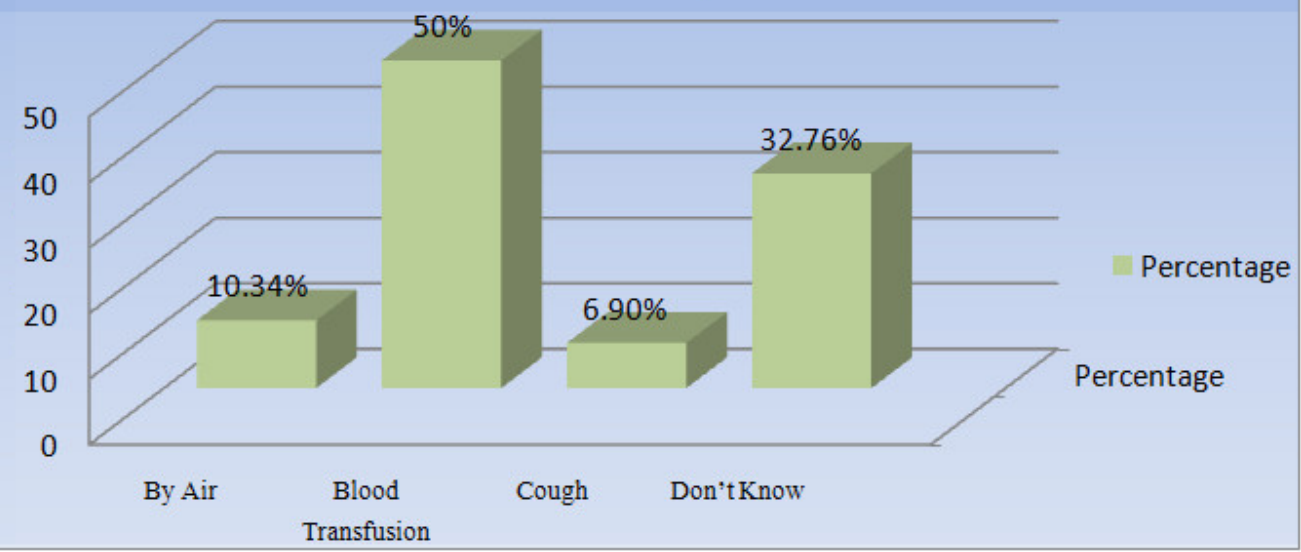

According to this figure-4, a large (50\%) number of the respondents think of HIV spreading by blood transfusion, and $(10.34 \%)$ by air, $(6.90 \%)$ by a cough, and $(32.34 \%)$ of the respondents doesn't know by spreading of HIV.

Table-5: Distribution of the respondents by the main source of HIV / AIDS infection.

\begin{tabular}{|l|c|c|}
\hline Source of HIV/AIDS infection & Frequency & Percentage \\
\hline Unsafe physical relation & 66 & 56.90 \\
\hline Sharing of infected needles/syringes & 10 & 8.62 \\
\hline Blood transfusion & 10 & 8.62 \\
\hline Mother to child & 2 & 1.72 \\
\hline Sex with HIV infected people & 4 & 3.45 \\
\hline All of Above & 6 & 5.17 \\
\hline Don't know Total & 18 & 15.52 \\
\hline \multicolumn{1}{|c|}{$\quad 116$} & $100 \%$ \\
\hline
\end{tabular}

In this table 5 shows that, the majority $(56.90 \%)$ of respondents have the knowledge that the most important source of HIV/AIDS infection by unsafe physical relation. Rest of $(8.62 \%)$ by sharing of infected needles \& blood transfusion. Only $(1.71 \%)$ by mother to child, $(3.45 \%)$ by sex with HIV-infected people, and $(5.17 \%)$ by all of above, $(15.52 \%)$ by don't know of HIV / AIDS infection.

Table 6: Distribution of the respondents by knowledge of prevention of HIV infection

\begin{tabular}{|l|c|c|}
\hline Prevention & Frequency & Percentage \\
\hline Protected sexual relation & 54 & 46.55 \\
\hline By using germfree needles/syringes & 28 & 24.14 \\
\hline By following religious norms & 8 & 6.89 \\
\hline Don't know & 18 & 15.52 \\
\hline Others & 8 & 6.90 \\
\hline Total & 116 & $100 \%$ \\
\hline
\end{tabular}

According to this table-6, the majority (46.55\%) of respondents by their knowledge the prevention of HIV / AIDS infection by unsafe physical relation, $(24.14 \%)$ by using germfree needles, $(6.89 \%)$ by following religious norms, and (15.52\%) by don't know prevention of HIV / AIDS infection. 
Table 7: Distribution of the respondents by the signs and symptoms of HIV / AIDS patients

\begin{tabular}{|l|l|l|}
\hline Signs and Symptoms & Frequency & Percentage \\
\hline Rapid weight loss & 13 & 11.21 \\
\hline Dry cough for more than 2/3 months & 11 & 9.48 \\
\hline Recurring fever for more than 2/3 months & 9 & 7.76 \\
\hline Diarrhea lasting more than a week & 6 & 5.17 \\
\hline Don't know & 75 & 64.66 \\
\hline Others & 2 & 1.72 \\
\hline Total & 116 & $100 \%$ \\
\hline
\end{tabular}

This table-7 shows that the majority (64.66\%) of the respondents don't know signs and symptoms of HIV/AIDS. But (11.21\%) of the respondents knowing by rapid weight loss, $(9.48 \%)$ by a dry cough for more than $2 / 3$ months, $(7.76 \%)$ by recurring fever for more than $2 / 3$ months, and $(5.17 \%)$ by diarrhea lasting more than a week.

Figure-5: Distribution of the respondents by knowing the treatment of HIV / AIDS.

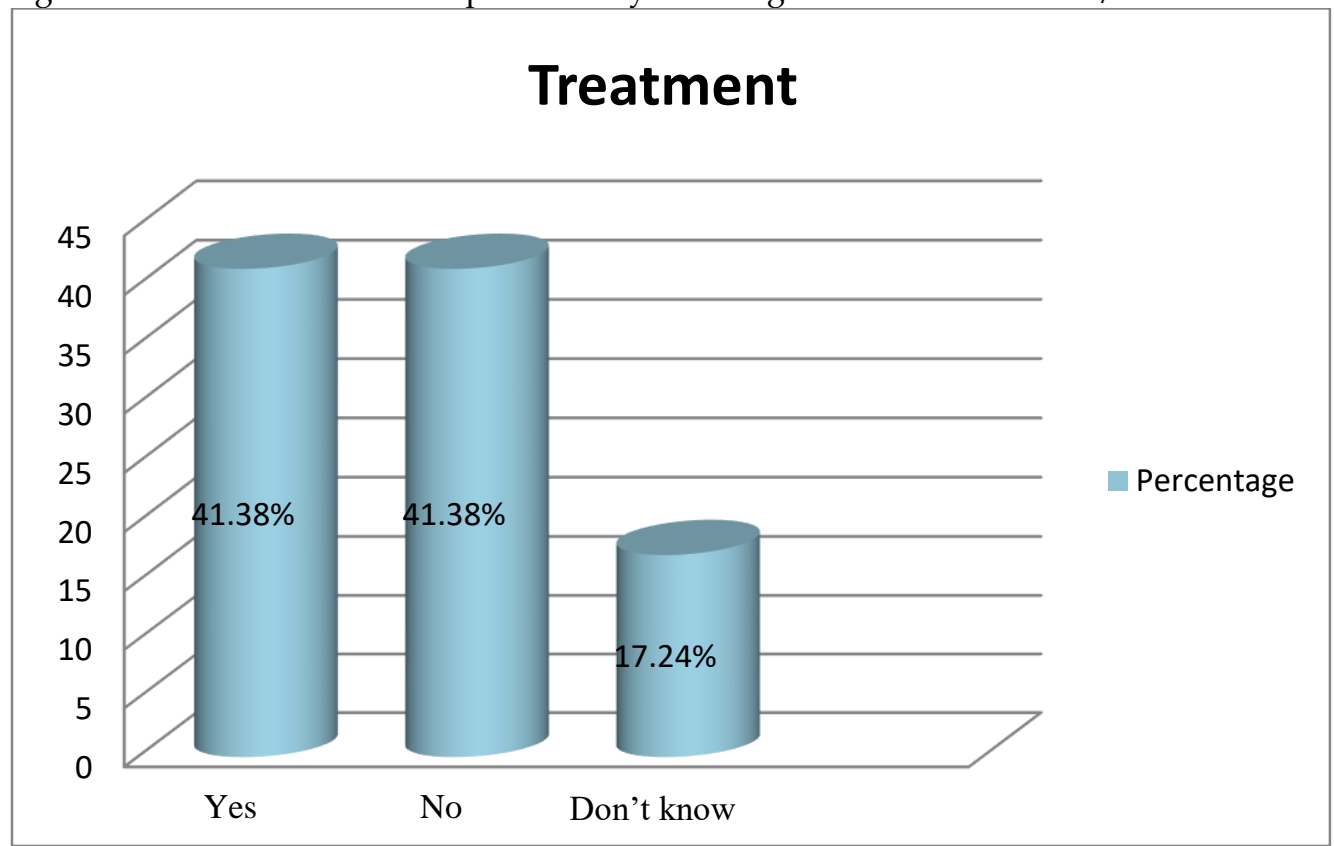

This figure- 5 shows that the HIV / AIDS cure by treatment is $(41.38 \%)$ of the respondents are the response by yes \& no. And (17.24\%) of the respondents are the response by don't know.

Table-8: Distribution of the respondents by knowing the HIV test availability.

\begin{tabular}{|l|l|l|}
\hline Answer & Frequency & Percentage \\
\hline Yes & 26 & 22.41 \\
\hline No & 38 & 32.76 \\
\hline Don't know & 52 & 44.83 \\
\hline Total & 116 & $100 \%$ \\
\hline
\end{tabular}

According to this table-8, the great (44.83\%) numbers of the respondents don't know where HIV tests availability. But other respondents were $(22.41 \%)$ response by yes, and $(32.76 \%)$ response by no. 
Table 9: Distribution of the respondents by HIV/AIDS patients has been isolated from society

\begin{tabular}{|l|l|l|}
\hline Answer & Frequency & Percentage \\
\hline Yes & 12 & 10.34 \\
\hline No & 104 & 89.66 \\
\hline Total & 116 & $100 \%$ \\
\hline
\end{tabular}

According to this table-9 shows that a person having HIV/AIDS has been isolated from society, were $(10.34 \%)$ of the respondents are the response by yes, and $(89.66 \%)$ of the respondents are the response by no.

Table-10: Distribution of the respondents by knowing the consequences of HIV / AIDS.

\begin{tabular}{|l|l|l|}
\hline Consequences of HIV / AIDS & Frequency & Percentage \\
\hline Death & 54 & 46.55 \\
\hline There is no treatment & 8 & 6.90 \\
\hline Easily attacked by any disease & 4 & 3.45 \\
\hline Cannot be cured after treatment & 36 & 31.03 \\
\hline Don't Know & 14 & 12.07 \\
\hline Total & 116 & $100 \%$ \\
\hline
\end{tabular}

In this table-10 shows that the consequences of HIV/AIDS are response by the respondents, were $(46.55 \%)$ response by death. Rest $(6.90 \%)$ response by there is no treatment, (3.45\%) response by simply attacked by any disease, $(31.03 \%)$ response by cannot be cured after treatment, and (12.07\%) response by don't know.

Table-11: Distribution of the respondents by attending any kind of HIV/AIDS-related awareness program in your slum.

\begin{tabular}{|l|l|l|}
\hline Answer & Frequency & Percentage \\
\hline Yes & 8 & 6.90 \\
\hline No & 108 & 93.10 \\
\hline Total & 116 & $100 \%$ \\
\hline
\end{tabular}

This table-11 shows that any type of HIV / AIDS-related awareness program in their slum by the response of the respondents, were $(6.90 \%)$ response by yes, and $(93.10 \%)$ response by no.

\section{CONCLUSION}

From the findings of the study, it can be concluded that slum dwellers have not enough knowledge about HIV/AIDS regarding their mode of transmission, high-risk groups, and consequences. However, their socio-economic status is not conducive to protect them from being attacked by disease. So, adequate knowledge is not enough to protect the slum from the grip of the HIV/AIDS. The result of this study revealed that knowledge and Behavior are not so good along with the slum dwellers in Dhaka city. Here still misconceptions regarding HIV transmission and prevention. They have lots of miss concept about the HIV / AIDS though they learned a little through media. To provide proper knowledge different steps may be taken. Still now many slum dwellers believe that HIV/AIDS may spread by casual contacts. The most essential find out of the study is that most of them still feel shy to talk about HIV / AIDS which is a great threat of our society. They hardly argue the topic, and that's why they are still living beneath the dark. They evidently don't know about the most dangerous pathological site of the HIV/AIDS. They only know that it is a sin and when once get HIV contaminated he/she will be neglected and isolated by the society and ultimately it is a disease of sin. They hardly believe that a neonate or child also be the victim of this worldwide threat. So to make them clear about the matter steps may be taken. 


\section{RECOMMENDATION}

- $\quad$ Positive mass awareness program on HIV / AIDS have been undertaken and strengthening effectively to make the people more aware regarding detail of HIV/AIDS, couched using different mass media. So common people will be informed about the scenery.

- Partial knowledge is a little bit harmful to the people especially if it is about the infection. The people found incomplete knowledgeable with some wrong perception about HIV / AIDS. Before designing any program in this regard, this finding could be considered.

\section{REFERENCES}

Amanullah, A. S.M. (2012) Current status of HIV/AIDS in Bangladesh, University of Dhaka, Vol.1, pp. 283-284.

Azim T, Islam MN, Bogaerts J, Mian MA, Sarker MS, Fattah KR (2000), Prevalence of HIV and syphilis among high-risk groups in Bangladesh. Vol.1, pp 28-32.

Emmanuel OO, Ifeanyi OT (2015). Seroprevalence of HBsAg//HIV among Pregnant Women Attending State Hosiptal Antenatal Clinic, Ijebu-Ode. Malaysian Journal of Medical and Biological Research, Volume 2. No 3.

Estivill J. (2003), 'Concepts and strategies for combating social exclusion: an overview', Geneva: International Labour Organization, pp. 137.

Ghafoor A and Khan AA. 2014. Emperical Study about Fears and Misconceptions of Aids and Hepatitis among Medical Students Malaysian Journal of Medical and Biological Research, 1, 25-34.

Hadhrami, S., Saaban, A., Ibrahim, A., Shahzad, M., \& Ahmad, I. (2014). Linear Active Control Algorithm to Synchronize a Nonlinear HIV/AIDS Dynamical System. Asian Journal Of Applied Science And Engineering, 3(2), 151-168.

Haider M, Ahmed SN, Nilufar K. Jaha. (2011), Bangladesh Med Res Council Bull; volume. 34, pp. 5461. And available from http:/ / www.bmrcbd.org/bulletin-34-2 aug08/Review\%20Paper.pdf

ICDDR, B, (2005). Health and Science Bulletin: Center for Health and Population Research; 3(1).

Masanja, M. (2015). Education Levels among Parents and Misconceptions on HIV and AIDS. Asian Business Review, 4(3), 27-30.

Masanja, M., \& Msuya, J. (2014). Social Changes Imposed by HIV and AIDS in Rural Areas: An Empirical Evidence of Sex Education in Maswa District, Tanzania. Asian Journal Of Applied Science And Engineering, 3(3), 309-320.

MOHFW,(2011). National AIDS/STD Program, Directorate General of Health Services, Ministry of Health and Family Welfare (MOHFW), Dhaka, Bangladesh

Rahman MS, Rahman ML (2007), 'Media and education play a tremendous role in mounting AIDS awareness among married couples in Bangladesh', AIDS Res Their, vol. 4, pp. 10

Suhadolnik(2007), "Socio-Demographic Covariates Play a Tremendous Role in Mounting HIV / AIDS Awareness, Knowledge among Slum Women in Bangladesh", Vol.8 (3), pp. 250-255.

UNAIDS, (2012) Global report: "UNAIDS report on the global AIDS epidemic" Available from:http://www.unaids.org/bangkok2012/report.html

Unicef, (2010). "HIV and AIDS in Bangladesh" Available from: http:/ / www.unicef.org/bangladesh/HIV \& AIDS (1).pdf 